\title{
A REALIZAÇÃO IMAGINÁRIA DO DESEJO INCONSCIENTE NUM GRUPO TERAPÊUTICO DE CRIANÇAS EM IDADE PRÉ-ESCOLAR
}

Jefferson Silva Krug e Nedio Seminotti

\author{
Jefferson Silva Krug \\ Psicólogo, mestre \\ em Psicologia \\ Clínica, doutorando \\ em Psicologia, \\ professor da \\ faculdade de \\ Psicologia \\ da PUCRS, \\ coordenador do \\ curso de Psicologia \\ da Faccat.
}

Nedio Seminotti Psicólogo, doutor em Psicologia pela Universidad Autónoma de Madrid, professor do PPG em Psicologia da PUCRS
RESUMO: Alguns teóricos têm observado que os grupos, assim como os sonhos, podem fornecer um espaço privilegiado para a realização imaginária de desejos inconscientes de seus membros. Por meio de relatos de sessões de um grupo terapêutico formado por crianças em idade pré-escolar, objetivou-se conhecer as formas de organização e de expressão do grupo que possibilitaram a realização imaginária de desejos inconscientes de seus membros. Mediante Análise Textual Qualitativa, constatou-se que a realização dos desejos foi possível pela articulação dinâmica entre desejos manifestos, formas de expressão e modos pelos quais o grupo organiza seus processos, influenciados pelas características do desenvolvimento psicossexual das crianças.

Palavras-chave: Psicanálise, psicoterapia de grupo, desenvolvimento psicossexual, período de latência.

ABSTRACT: Imaginary achievement of unconscious desire in a therapy group of pre-school-aged-children. A few theoreticians have observed that groups, as well as dreams, may provide a privileged space for the imaginary achievement of their members' unconscious desires. Through reports of sessions of a therapy group comprising children at pre-school age, this study aimed at learning the organization and expression forms of the group that rendered possible the imaginary achievement of their members' unconscious desires. Qualitative Textual Analysis led to find out that the achievement of desires was possible through the dynamic articulation among the expressed desires, forms of expressions and ways in which the group organizes its processes, influenced by the characteristics of the children's psychosexual development.

Keywords: Psychoanalysis; group psychotherapy; psychosexual development; latency. 
A utores como Weinmann (2002), Hanns (1999) e Brasiliense (1999) postulam que o conceito de desejo inconsciente possui um importante status na teoria psicanalítica, havendo, pois, a necessidade de trabalhos que busquem aprofundamento contínuo deste construto na prática psicanalítica. Assim, este trabalho propõe a articulação deste conceito à psicoterapia de grupo.

Tomando como referência básica autores que versam sobre a realização imaginária de desejos inconscientes nos grupos (ANZIEU, 1993; DECHERF, 1986; KAËS, 1997, 2002; OLIVEIRA, 2002) e a analogia entre o grupo e o sonho, este estudo voltou-se para o seguinte questionamento: quais foram as formas de organização e de expressão, em um grupo terapêutico de crianças, que possibilitaram a realização imaginária dos desejos de seus membros?

Visando responder a tal problema de pesquisa, tentou-se compreender como um grupo terapêutico de crianças em idade pré-escolar possibilitou a realização imaginária de desejos inconscientes de seus membros procurando identificar quais desejos estavam presentes neste grupo, a dinâmica de sua organização e quais foram as formas de expressão dos mesmos.

\section{O DESEJO INCONSCIENTE NOS GRUPOS INFANTIS}

A leitura criteriosa dos textos freudianos Projeto para uma psicologia científica (FREUD, 1895/1987) e Interpretação dos sonhos (FREUD, 1900/1987) leva-nos a constatar a importância capital que o conceito de desejo inconsciente alcança no pensamento de Freud, tanto durante o desenvolvimento de sua primeira teoria do aparelho psíquico, como no restante de sua obra (GAY, 1999; VALLS, 1995). Ele acreditava que todas as ações do ser humano seriam, de alguma maneira, influenciadas pelos desejos inconscientes. Para ele, uma das saídas encontradas pelo psiquismo para atingir tal objetivo seria a produção de alucinações visando reencontrar uma vivência de satisfação experimentada pelo sujeito durante os primeiros anos de vida.

No estudo sobre os sonhos, Freud relacionou a realização alucinatória de desejos inconscientes à construção de cenas e associações de imagens durante a vida onírica. Este achado levou-o a compreender os sonhos como uma produção do psiquismo voltada para a satisfação parcial de um estado de tensão desejante, dando aos sonhos um status privilegiado de acesso aos desejos inconscientes. Portanto, o sonho seria o lugar de acesso e trabalho dos fenômenos psíquicos, sendo esta capacidade um resultado do processo terapêutico formador de um campo potencial criado pela dupla paciente-analista (GROMANN \& BERLINCK, 2003).

Com base nesta hipótese teórica, Anzieu (1993), Decherf (1986), Kaës (1997, 2002) e Oliveira (2002) têm discutido uma nova forma de pensar os processos 
grupais pela reflexão acerca da realização dos desejos inconscientes no grupo. Essa reflexão só foi possível a partir do estabelecimento da analogia entre o grupo e o sonho, primeiramente apresentada por Anzieu (1993).

Decherf foi o que mais se dedicou ao estudo do tema nos grupos terapêuticos infantis. Ele ressalta a função continente do enquadre, entendido como uma espécie de matriz na qual as crianças poderão expressar seus desejos por meio de elementos variados que constituem cadeias associativas semelhantes à associação livre. A situação de grupo possibilitaria a "cada um reconhecer ou projetar no outro as pulsões ou desejos nele recalcados" (1986, p.80).

Franco (2003), ao descrever o brincar e a experiência analítica com base em Winnicott, refere-nos que a criança leva para a sessão-espaço-de-brincadeira elementos de experiências oriundas da realidade socialmente sustentada e os usa como elementos de enriquecimento e transformação no campo transicional, com efeitos no mundo interno. Embora a sessão terapêutica não inclua uma alucinação como no sonho, acaba por tornar-se um espaço de passagem entre o mundo interno e o mundo externo, estando, em algumas vezes, impregnada com sentidos oníricos de experiências ocorridas na realidade social.

Oliveira (2002) buscou estudar os desejos manifestados num grupo natural de crianças pré-escolares e concluiu que o principal desejo presente no grupo estudado foi o de ser adulto. Este se manifestou de diferentes formas, configurando seis categorias: desejo de ter uma vida sexual como a dos adultos, ter um comportamento protetor como o dos pais, utilizar objetos mais característicos de pessoas adultas, realizar atividades típicas dos adultos, ter características inerentes aos adultos quanto à autonomia e poder e, finalmente, usar expressões verbais características dos adultos.

"Considero que as produções lúdicas observadas no grupo natural de crianças préescolares foram realizações de desejos, produtos do inconsciente. Posso concluir que o grupo, como o sonho, exerceu uma função de realização imaginária dos desejos irrealizados e proibidos no ambiente familiar dessas crianças." (OLIVEIRA, 2002, p.81)

As conclusões desta pesquisadora se apoiam na observação das produções lúdicas e nas diferentes formas de comunicação entre as crianças do grupo. Portanto, para investigar as manifestações dos desejos inconscientes das crianças de um grupo, é necessário atentar para a palavra, o gesto e o brinquedo que, segundo Decherf (1986), participam de um mesmo movimento que permite a expressão de um desejo ou de um fantasma inconsciente.

Segundo Sigal (1989), o grupo de crianças proporcionaria ao pesquisador a possibilidade de observar com especial riqueza diversos fenômenos psíquicos, 
dentre os quais a emergência do desejo inconsciente. Tanto para Anzieu (1993), como para os demais autores citados, além da palavra, do gesto e do brinquedo, também seria possível identificar a manifestação de alguns desejos inconscientes no grupo por meio dos organizadores grupais nele instituídos.

\section{OS ORGANIZADORES DE GRUPO}

Podemos mencionar a presença de três tipos de organizadores nos grupos terapêuticos: os organizadores formais, os organizadores socioculturais e os organizadores psíquicos. Os dois primeiros dizem respeito às normas e à incidência de aspectos socioculturais sobre os grupos. Eles possibilitam uma espécie de matriz, na qual aspectos transferenciais, ideológicos, identificatórios e transgressores poderão ser vividos. Os organizadores formais seriam a tarefa do grupo, os papéis e o enquadre (lugar onde ocorre o grupo, hora do encontro, duração da sessão, frequência do acompanhamento etc., cf. CUETO \& FERNANDEZ, 1985; SEMINOTTI, 2003; SEMINOTTI, CRUZ \& BORGES, 2004). Já as representações ideológicas, utópicas, míticas, científicas e institucionais configurariam o que Kaës (1997) chamou de organizadores socioculturais, e teriam como função normatizar, através de códigos sociais (valores e normas culturais), a realidade psíquica do grupo.

O terceiro tipo de organizador pode ser definido como "uma estrutura e uma forma da realidade psíquica inconsciente, capaz de desempenhar um papel no arranjo e no desenvolvimento dos vínculos grupais e na relação de cada sujeito com a unidade grupal” (KAËS, 1997, p.175). Os organizadores psíquicos são formações inconscientes complexas que possibilitam, sustentam e expressam os vínculos no grupo. Anzieu (1993) sugere a existência de cinco organizadores psíquicos inconscientes grupais (fantasma individual, imago, fantasmas originários, complexo de Édipo e envelope psíquico do aparelho grupal). Destes, nos deteremos em dois: a imago e os fantasmas originários.

Segundo o autor, a imago seria o organizador mais simples e que provocaria ressonância com maior facilidade entre as pessoas. Isso se deve ao fato de que a imago é entendida como sendo historicamente construída no transcorrer do desenvolvimento da espécie, pré-existindo, pois, de forma potencial em todos os indivíduos. Ela emergiria como organizador do grupo quando a estrutura latente do aparelho grupal é marcada pela predominância de uma das instâncias reguladoras do aparelho psíquico individual: Ideal de Ego, o Ego Ideal e o Superego.

Com o desenvolvimento do grupo, é provável que os seus participantes se apoiem nos fantasmas originários ou protofantasias que organizam suas relações. Esse organizador remete à origem do indivíduo, à diferença dos sexos e à origem 
da sexualidade, e forneceria ao grupo a aquisição de sistemas de oposição mais elaborados que o caráter bipolar oferecido pela imago.

Decherf (1986) afirma que nos grupos de crianças a organização grupal transcorre a partir de uma evolução de fantasmas. Este autor descreve três organizadores: a) Sideração Grupal ou Imago materna precoce, momento inicial de todos os grupos, quando as crianças procuram se manter indiferenciadas, na tentativa de criar um grupo familiar ideal; b) Imago Paterna, fase inaugurada a partir da recusa dos analistas em manejar o grupo de maneira diretiva, obrigando as crianças a elegerem um líder que comporta, ao mesmo tempo, um caráter de interdição da realização plena dos desejos e uma imago materna mais evoluída (portadora do desejo); e c) Fantasmas Originários, quando fantasias relativas à vida intrauterina, à diferença entre sexos e à origem poderão ser expressas e trabalhadas até uma crescente melhora no processo de comunicação entre a vida consciente e a vida inconsciente dos membros do grupo.

A Sideração Grupal, primeiro organizador psíquico dos grupos, expressa um momento mais primitivo do desenvolvimento psicossexual, no qual não há, ainda, uma diferenciação clara entre o eu e o meio. Encontramos algumas semelhanças entre a Sideração Grupal de Decherf (1986) e o conceito de Ilusão grupal descrito por Anzieu (1993). Este último se refere a um momento inicial do grupo no qual a realidade exterior é posta em suspenso, como no sonho. Esse momento narcísico possibilitado por uma espécie de "continente grupal" tenderá a se desfazer ao longo do tempo. Enquanto isso não acontece, poderá se evidenciar uma tentativa dos membros de criar um grupo familiar ideal, uma prole “sem Édipo”, sem diferenças, sem conflitos (DECHERF, 1986). Desta forma, a ameaça ao narcisismo individual é compensada com a criação de uma espécie de narcisismo do grupo. Do ponto de vista tópico, a ilusão grupal faz referência a um estado arcaico do Ego, herdeiro do narcisismo primário, ilustrando um momento de Ego Ideal projetado sobre o grupo.

O segundo organizador de grupo, do ponto de vista de Decherf (idem), é a Imago Paterna, descrita pelo autor como o momento mais importante do grupo. Esse organizador emerge quando os membros do grupo buscam proteger suas identidades e seus fantasmas individuais ali ameaçados. Para tal, as crianças conduziriam os acontecimentos visando estruturar o grupo no qual haveria um líder autoritário, transformando-o em um grupo diretivo.

Os Fantasmas Originários, terceiro organizador descrito por Decherf (1986), emergem assim que o grupo vivencia uma lei tranquilizadora proporcionada pela Imago Paterna. Nesta etapa da evolução, o grupo consegue unir-se em torno de fantasmas compartilhados por todos os seus membros. A esse fato segue-se, ainda, uma ampliação gradual da capacidade de comunicação entre a vida consciente e a vida inconsciente. 
Portanto, visando ilustrar tais conceitos abordados pela literatura, descreve-se a seguir a pesquisa realizada.

\section{CONTEXTO DA PESQUISA}

Por meio de um convênio firmado entre o Serviço de Atendimento Psicológico da PUCRS (SAP) e uma creche comunitária localizada no município de Porto Alegre, acadêmicos do Curso de Psicologia podem desenvolver atividades de estágio com práticas grupais planejadas e organizadas de acordo com as demandas trazidas pela comunidade. Ao longo do acompanhamento dos grupos coordenados pelos estagiários, são produzidos relatos escritos dos encontros com o objetivo de supervisionar a prática terapêutica. Este material é arquivado pelo SAP para fins de pesquisa e orientação de futuras intervenções.

Nesse contexto, inicialmente foram realizados quatro encontros com 29 alunos que compunham uma turma do Jardim B da referida creche para fazer um levantamento das demandas a serem trabalhadas naquele grupo e verificar quais crianças mais precisariam de acompanhamento psicológico. Desde os contatos preliminares, a educadora responsável pela turma apontava a sexualidade e a agressividade como os aspectos que mais necessitavam ser trabalhados. As perguntas mais frequentes das crianças aos estagiários se relacionavam à temática da diferença entre sexos, revelando que viam os dois (Jefferson e Patrícia) como namorados.

A escolha das crianças que participariam do grupo foi feita com base na observação destes primeiros encontros, juntamente com a opinião da professora responsável pela turma (aqui chamada de Maria). Foram selecionadas as crianças que aparentavam maior necessidade de tratamento e condições para aproveitar um acompanhamento terapêutico desta natureza. Após esta etapa, foi solicitado aos responsáveis o consentimento para a participação das crianças no grupo.

Estes alunos passaram a compor um pequeno grupo com os terapeutas, enquanto os outros permaneciam brincando no pátio, na companhia da professora. O acompanhamento terapêutico teve a duração de 12 encontros, cujos relatos constituíram o material para análise.

\section{MÉTODO}

Esta pesquisa seguiu um modelo qualitativo de investigação, operacionalizandose através de um estudo de caso (GOLDENBERG, 1998). Na área de pesquisa em psicologia dos grupos, se denomina estudo de caso a exploração em profundidade de um único grupo com o fim de descrever sua natureza, composição, estrutura relacional, as trocas e as funções de seus membros (ÁLVAREZ, 1997). 
Desta forma, a presente pesquisa partiu da análise documental (CONTANDRIOPOULOS, CHAMPAGNE, POTVIN, DENIS, BOYLE, 1997) dos 12 relatos das sessões do grupo terapêutico descrito. Este grupo terapêutico foi coordenado pelos estagiários já mencionados, sendo um deles responsável pela presente pesquisa.

\section{PARTICIPANTES}

O grupo foi composto por oito crianças (quatro meninos e quatro meninas), com idades compreendidas entre 5 e 6 anos, que apresentavam dificuldades relacionais de diferentes níveis, naturezas e intensidades (dificuldades de aprendizagem, agitação psicomotora, agressividade, entre outros). Os encontros ocorriam semanalmente em uma sala de aula da própria creche, com duração de uma hora. Para o desenvolvimento deste grupo, foram seguidas as indicações técnicas descritas por Decherf (1986) quanto à composição, indicações e contraindicações.

Este trabalho seguiu as recomendações do Conselho Nacional de Saúde (BRASIL, 1996) relativas à pesquisa com seres humanos.

\section{PROCEDIMENTO PARA A ANÁLISE DOS DADOS}

O material coletado junto ao SAP (serviço que detém a guarda dos relatos provenientes da atuação de seus estagiários) foi submetido à Análise Textual Qualitativa, seguindo os passos sugeridos por Moraes e Galiazzi (2007). Primeiramente, foram feitas leituras do material a ser analisado para depois fragmentá-lo em unidades de sentido. Num terceiro momento, essas frações dos relatos foram agrupadas de acordo com a semelhança entre os sentidos emergentes contidos em cada uma. Formou-se, desta maneira, um primeiro agrupamento de unidades de sentido que deu origem ao processo de categorização inicial. Para tal, realizou-se uma leitura exaustiva das unidades de sentido — desta vez, agrupadas - a fim de propiciar uma compreensão mais profunda sobre o tema aglutinador de cada categoria inicial. O agrupamento das categorias iniciais que possuíam um elo deu início ao processo de construção de categorias intermediárias. Por fim, o estabelecimento de relações entre essas categorias intermediárias resultou na confecção de três categorias finais.

\section{APRESENTAÇÃO E DISCUSSÃO DOS RESULTADOS}

Finalmente, após a execução dos procedimentos de análise dos relatos, foram construídas 44 categorias iniciais, 13 intermediárias e três finais referentes à realização do desejo inconsciente no grupo, apresentadas na Figura 1. Observou-se 
que três grandes temas destacaram-se durante a análise dos dados. Seus conteúdos fazem referência aos desejos manifestos pelas crianças, aos tipos de organização grupal e às formas de expressão destes desejos no grupo.

Os desejos manifestos no grupo foram o de entrar na primeira série, fazer amigos, conhecer-se, ser o preferido e crescer. A organização do grupo sofreu influência de diferentes fatores, todos eles agrupados em três categorias intermediárias: organizadores psíquicos, organizadores socioculturais e organizadores formais. Por fim, as formas de expressão presentes no grupo foram divididas em tipos de interações, sentimentos, modalidades defensivas, angústias e identificações. Cada uma das categorias intermediárias foi construída a partir da associação de categorias iniciais emergentes da leitura e análise dos dados.

$\mathrm{Na}$ fase inicial do acompanhamento, observamos que as crianças buscaram expressar seus desejos através de interações lúdicas e escritas, conforme sugerido por Decherf (1986) e Oliveira (2002). Nos primeiros três encontros, o grupo centralizou-se em torno da tentativa de escrever nomes e palavras, como se pode observar na seguinte passagem do relato analisado:

$1^{\circ}$ ENCONTRO | Constatamos que as crianças queriam nos mostrar como sabiam ler e escrever, Iago faz a letra I de seu nome, Manuel o M e David o D. Leonardo fazia bolinhas referindo-se a elas como letras.

O fenômeno da sideração grupal (DECHERF, 1986) ou ilusão grupal (ANZIEU, 1993) se evidenciou neste estudo durante a análise dos primeiros encontros. Nestes, a vivência de uma ilusão de que o grupo era formado apenas pelas crianças da turma que sabiam ler e escrever também as ajudou a se organizar, mantendo os seus membros momentaneamente indiferenciados.

$1^{\circ}$ ENCONTRO | Algumas crianças diziam que aquele (o grupo terapêutico) não era lugar delas (outras crianças que não faziam parte do grupo e que espiavam na porta da sala) e que somente as crianças que sabiam ler e escrever podiam ficar ali no grupo(...)

Este dado vai ao encontro do que Padilha e Moraes (2004) também identificaram em seus grupos, o fenômeno da ilusão grupal, compreendendo-o como um fator aglutinador que permite ao grupo a subsistência frente a um movimento grupal de intensa frustração. No grupo estudado, todos os aspectos rejeitados eram projetados nas crianças que não faziam parte deste, enquanto os atributos desejados eram identificados como pertencentes aos membros do grupo. Segundo Anzieu (1993), há nesta ordenação de grupo a incidência de uma dissociação na qual seus membros projetam a pulsão de morte sobre outro grupo ou sobre um membro, permitindo que os demais gozem um laço puramente libidinal entre si. Conforme Quinodoz (2004), o recurso às defesas primitivas, em especial as 
narcísicas, visa, por um lado, permitir ao ego proteger-se contra a percepção do objeto como separado e diferente do ego e, por outro, fazer com que o ego confunda-se com o objeto idealizado, a fim de não deixá-lo e de unir-se a ele. Valadares e Villani (2004) afirmam que essa ilusão grupal, imagem de um coletivo "bom” que consegue resolver suas tarefas, estrutura os desejos do grupo e os objetivos que ele acredita poder realizar. Estaria em jogo aí, também, o fenômeno de amor transferencial, quando o analista ou, aqui, o grupo, passa a ser alvo do desejo das crianças que dele fazem parte. Por meio desse amor poderá surgir uma relação sustentadora da análise, a relação de suposto saber.

Essa transposição do desejo do analisante (no caso, os integrantes do grupo) à imagem do analista (no exemplo, o grupo e seus coordenadores) também traz consigo as idealizações e simbolizações, representando, no campo analítico, suas cristalizações dentro das relações objetais (ALMEIDA \& ATALLAH, 2008). Assim, observou-se o uso de defesas primitivas, como negação e dissociação, que elevaram paulatinamente a angústia na sala, promovendo uma regressão parcial e temporária no grupo. O momento inicial de ilusão grupal estabelecido no grupo foi, aos poucos, substituído pela necessidade das crianças de serem destinatárias de uma atenção individualizada por parte dos coordenadores e demais membros. Essas situações possibilitaram a manifestação de outros desejos, viabilizando, assim, o desenvolvimento de novas formas de interação, resultado da elevação da angústia de aniquilamento proveniente da impossibilidade de realização plena dos desejos de todas as crianças naquele espaço coletivo:

$2^{\circ}$ ENCONTRO | Um grupo de meninas provocou Ane, puxando seus cabelos e batendo em suas costas.

$2^{\circ}$ ENCONTRO | Junto ao papel pardo, Joana e Davi brigavam muito, pois a menina queria colar uma figura sobre o desenho do colega.

$2^{\circ}$ ENCONTRO | Perguntamos o que eles queriam fazer no grupo e respondem que querem aprender a fazer amigos e a não brigar mais.

Estabeleceu-se então, uma alternância de organizadores de grupo, emergindo situações de conflito, expressas com brigas e gritos na sala. Para lidar com tal situação foi necessário, como descrito por Decherf (1986), a eleição de um líder. Por isso, algumas vezes uma das crianças assumia o papel da educadora tentando organizar a sala como esta fazia.

$3^{\circ}$ ENCONTRO | Joana dizia o que era e o que não era permitido pela professora. A menina parecia muito preocupada com as regras que a professora Maria impunha para a turma, tentando controlar quem as burlasse.

A partir do terceiro e quarto encontros, os membros do grupo começaram a desenhar e esculpir com massinhas de modelar símbolos fálicos. Em decorrên- 
cia disto, as crianças passaram a manifestar curiosidade pelas diferenças entre meninas e meninos.

$3^{\circ}$ ENCONTRO | Iago desenhava o que chamou de 'pinto de fazer xixi'. Logo, as meninas começaram a se aglomerar sobre ele para ver sua produção e Mariela diz que aquilo era um pênis.

$4^{\circ}$ ENCONTRO | Alex conta que Iago beija os meninos e acha que é menina, pois quer usar saia e batom.

Este movimento do grupo repetiu-se ao longo dos 12 encontros, mas com uma diminuição nos últimos. Observava-se nas crianças ora o desejo de saber mais sobre o assunto sexual, ora o temor e a culpa pela curiosidade. Desde então, as manifestações e o interesse quanto à sexualidade passaram a se apresentar de forma intensa, tanto no grupo como fora deste, o que foi observado pela educadora responsável pela turma.

A partir do quinto encontro, com o desenvolvimento do interesse por assuntos referentes à sexualidade, intensificou-se a vivência da angústia de castração, resultando na necessidade de uma divisão das crianças em dois subgrupos (meninos e meninas). Além disso, as crianças passaram a manifestar comportamentos ligados à identificação com um coordenador de mesmo sexo como forma de buscar um novo organizador para lidar com a angústia predominante naquele momento:

$5^{\circ}$ ENCONTRO | Joana senta ao lado de Patrícia e pergunta: 'tia, quando tu era criança como nós tu também pensava em casamento?'. A questão foi devolvida ao grupo também sob forma de pergunta e este se desorganiza muito, com diversas crianças gritando e chorando.

$6^{\circ}$ ENCONTRO | A sala encontrava-se dividida: os meninos aglomeravam-se sobre Jefferson e as meninas permaneciam junto de Patrícia.

Além disso, o grupo passou a se questionar sobre as relações familiares a partir de diversos desenhos de reis, rainhas e princesas, formando histórias com claras alusões edípicas. Estas foram identificadas no sexto encontro a partir do questionamento do grupo sobre qual seria o futuro da princesa: casaria com o rei e expulsaria a rainha de casa ou procuraria um príncipe para um dia ser uma rainha como sua mãe?

A análise integrada dos dados sugere que as crianças do grupo estudado estavam vivenciando, no momento da intervenção, a operação psíquica relativa à saída edípica e à entrada no período de latência. Isso ficou mais claro entre o quinto e o oitavo encontros. Por meio de comportamentos desafiadores, buscavam elaborar a conflitiva edípica, questionando e incitando a posição superegoica dos coordenadores perante elas. 
$7^{\circ}$ ENCONTRO | Joana não permitia que ninguém guardasse o quebra-cabeça. Quando Jefferson colocava as peças na caixa, a menina jogava as peças no chão novamente.

Esses fatos continuaram a se repetir nos encontros subsequentes, surgindo mais questionamentos sobre a diferença entre masculinidade e feminilidade. Essas dúvidas eram acompanhadas de manifestações desafiadoras, como não obedecer às regras do grupo, não atender aos chamados dos coordenadores e buscar irritá-los chamando-os de "tia Jeffersa" e "tio Patrício". Ao provocar os terapeutas, as crianças buscam fazer com que os coordenadores representem o protótipo inconsciente da imago paterna (organizador do grupo naquele momento), diminuindo a possibilidade da associação pluriexpressiva e levando os coordenadores a adotar uma espécie de postura superegoica proibitória. Segundo Decherf (1986), o que estaria em jogo, na realidade, seria o desejo inconsciente do incesto, e as interdições do grupo seriam uma espécie de deslocamento da proibição do incesto.

Este movimento apaziguou-se gradativamente, de forma que foi possível observar uma diminuição na preocupação das crianças com as diferenças sexuais. Esse fato relaciona-se ao surgimento de situações nas quais as crianças expressavam culpa, vergonha e rechaço por conteúdos da ordem da sexualidade.

$8^{\circ}$ ENCONTRO | Joana dizia que não era para falar de sexo: 'Vocês não lavam os ouvidos? Não é para falar disso!'

$8^{\circ}$ ENCONTRO | Gerson começa a chorar. Diz que se sente mal quando Iago lhe beija na boca. Gabriel diz que não quer mais falar naquele assunto: 'Eu não aguento mais isso!'

Segundo Kramer e Byerly (1996) e Tallaferro (1996), a fase da latência ocorre a partir dos cinco anos de vida, o que coincide com a idade destas crianças. No início deste período observa-se um paulatino decréscimo na expressão de conteúdos sexuais infantis, em virtude da ação do recalcamento. Segundo os autores, para Freud os sintomas psíquicos ou suas formações (sonhos, atos falhos e chistes) têm sua origem em conflitos entre a realização de um desejo e a realidade externa. A impossibilidade de realização do desejo inconsciente em função de sua incompatibilidade com a realidade externa (normas culturais) gera um conflito. Sua aparente resolução consiste em substituir esse desejo proibido por algo aceitável pelo ego e a realidade externa. O ego, para tal, fará uso de mecanismos de defesa, tais como o recalcamento. Por mais sofrimento que um sintoma possa causar, o desejo inconsciente, se fosse realizado, causaria desequilíbrio e angústia maiores ao ego. A utilização dos mecanismos de defesa visa, portanto, a evitar o sofrimento que a realização do desejo poderia provocar. A ação destes mecanismos durante o período da latência proporciona o desenvolvimento de 
algumas características na criança como a repulsa, a vergonha e os ideais morais, sendo que a consolidação destas características impede, temporariamente, a livre expressão da sexualidade (LAPLANCHE \& PONTALIS, 1988; SOIFER, 1987).

No entanto, a latência sexual é relativa, pois o que se opera é um recalcamento de desejos libidinais do período edípico devido à estruturação do ego e do superego. Anzieu (1993) lembra que no grupo essa estrutura se presentifica na adoção da imago como organizador do grupo, sendo esta seguida pela incidência da formação reativa contra os desejos libidinais incestuosos da fase edípica, com manifestações de nojo, repugnância e vergonha (KRAMER \& BYERLY, 1996). Freud atribui a ação da amnésia infantil ao período da latência, quando ocorre o desenvolvimento do mecanismo de sublimação e do instinto de investigação e a consolidação do ego ideal (SOIFER, 1987).

No grupo estudado, foi possível observar que as crianças dramatizaram a estruturação egoica e superegoica principalmente durante o período correspondente ao terceiro e oitavo encontros. Com uma organização pautada na Imago Paterna e de interações desafiadoras e agressivas voltadas principalmente para os coordenadores, as crianças puderam encontrar neste espaço coletivo um lugar de acolhimento e possibilidade de realização de desejos inconscientes. Essas situações, como bem pontua Lewis (1995), dizem respeito à necessidade da criança de testar a interdição imposta pelo terceiro e pela sociedade sobre seu desejo incestuoso de posse da figura do sexo oposto.

Por essas razões, Lewis (1995) diz que a adequada instauração do período da latência está diretamente relacionada à superação dos conflitos edipianos, refletida no estabelecimento do superego. Isso permitirá, também, que a criança desempenhe alguns papéis solicitados pelo social nesta idade como frequentar a escola e aprender questões tais como leitura, escrita e aritmética (BEE, 1997).

Para Soifer (1987), durante a latência, a curiosidade pela origem dos bebês, diferenças sexuais e vida íntima dos pais é substituída pelos desafios do aprendizado (escolares e extracurriculares). Sarnoff (1995) lembra que o estabelecimento do superego na latência inicial se reflete na aceitação dos valores sociais na escola e em outros meios, permitindo que a criança empregue energia e tempo para aprender pelo direcionamento da energia instintiva para atividades de dimensões psicossociais. Esse fato faz com que as relações interpessoais não sejam mais experimentadas com tanta tensão agressiva e sexual.

$\mathrm{Na}$ fase final do acompanhamento, percebemos que os membros do grupo passaram a manifestar certa tranquilidade em seus atos. Do oitavo ao último encontro, o grupo manteve-se dividido por sexos, porém já permitia o estabelecimento de uma comunicação mais desenvolvida entre os subgrupos. As crianças demonstravam maior interesse por letras e palavras, afirmando querer crescer e entrar na escola. Esses interesses por assuntos relacionados à escola, leitura e 
escrita sempre estiveram presentes no grupo estudado. No entanto, percebemos uma intensificação das interações verbais e escritas nos últimos encontros, assim como das atitudes de cooperação e da identificação entre as crianças como forma de tratar questões até então vividas de maneira muito conflituosa. Foi possível observar que nesta etapa do acompanhamento as crianças já haviam conseguido melhorar um pouco a expressão de seus afetos, desenvolvendo habilidades de comunicação e convivência com seus iguais, conforme previsto por Decherf (1986). Percebemos que as crianças, em geral, conseguiam manter-se sentadas na "rodinha" por mais tempo, apontando maior condição pessoal para se comunicarem de maneira verbal. Esse fato levou algumas crianças a ressaltar que haviam aprendido a fazer amigos no grupo.

$11^{\circ}$ ENCONTRO | Todas as crianças se escutavam e participavam da rodinha, onde permanecemos por aproximadamente 15 minutos conversando.

$12^{\circ}$ ENCONTRO | Espontaneamente, uma das crianças lembra que antes o grupo era uma bagunça, que existiam muitas brigas, mas que agora isso não ocorria mais.

O organizador psíquico predominante nesta fase foram as fantasias originárias, quando o grupo centrou-se na questão das origens e diferenças sexuais de maneira mais adaptativa:

$10^{\circ}$ ENCONTRO | No grupo do desenho, as crianças se questionavam de onde vem a família, e diziam que o grupo era uma família.

$11^{\circ}$ ENCONTRO | As crianças falavam sobre as semelhanças e diferenças entre seus nomes e lembravam que os nomes de meninas eram diferentes dos nomes de meninos.

A vivência das fases anteriores do grupo pareceu ter contribuído para o enfrentamento da saída edípica e a consolidação de um modelo superegoico menos rígido e mais afetivo. Na última sessão, a proposta de despedida do grupo (falar dos encontros anteriores) foi atendida de forma bastante madura pelas crianças, associando-se à despedida da creche e da professora Maria, uma vez que era o último ano das crianças ali.

\section{CONSIDERAÇÕES FINAIS}

Assim, a presente pesquisa possibilitou levantar alguns pontos importantes para a discussão da realização dos desejos inconscientes nos grupos terapêuticos infantis. Infere-se, a partir da análise das três principais categorias, que a realização dos desejos inconscientes no grupo operou-se mediante a articulação dos desejos manifestos, das organizações engendradas pelas crianças no grupo e por suas 
formas de expressão. Cada uma das categorias de análise descrita neste trabalho pode ser compreendida em separado, mas é na inter-relação das ideias principais lá contidas que constatamos que o grupo possibilitou, assim como em um sonho, a expressão de desejos e conflitos inconscientes de seus membros. Desta forma, os desejos dos participantes construíram uma organização do grupo, e esta organização contribui às manifestações dos desejos e sua realização imaginária.

A discussão dos dados sugere, ainda, que a compreensão em conjunto dos desejos dos membros do grupo, dos organizadores e das formas de expressão grupal pode auxiliar no diagnóstico da fase de desenvolvimento em que se encontram as crianças que o compõem. Esse fato se deve à observação de que as três categorias finais de análise também sofreram influência direta da peculiaridade da etapa do desenvolvimento psicossexual vivenciada pelas crianças, a saber, a saída edípica e a entrada na latência. Essa influência esteve presente, principalmente, na adoção, por parte dos membros do grupo, de características próprias da passagem fálica ao período de latência, no questionamento da posição superegoica dos coordenadores, no interesse pelas diferenças sexuais, no desenvolvimento do ego e do superego, no aparecimento de características como repulsa e vergonha por assuntos ligados à expressão de conteúdos sexuais, na ação do recalcamento e no direcionamento da energia libidinal para atividades de dimensões psicossociais, como escola e grupos de amigos.

Também foram evidenciados alguns fenômenos de grupo descritos na literatura (ANZIEU, 1993; CASTELLANOS \& SÁNCHEZ-ESCÁRCEGA; 2003; CODERCH, 1990; DECHERF, 1986; KAËS, 1997; KERNBERG, 1998; KRUG \& SEMINOTTI, 2006) que indicam que este dispositivo promove uma regressão de seus membros, assim como num sonho. A regressão cronológica ao narcisismo primário e secundário pôde ser observada principalmente no início do grupo, quando seus membros requeriam atenção individualizada e assim, em conjunto, apoiaram-se numa ilusão para negar diferenças e conflitos intrapsíquicos e intersubjetivos. A livre expressão dos desejos, mais próxima do processo primário, a tentativa de realizá-los no grupo, as formas de interação, os sentimentos e angústias manifestados, as modalidades defensivas utilizadas e as identificações operadas exemplificaram a regressão tópica e formal no grupo.

Portanto, os dados da pesquisa sugerem que o grupo pode se constituir em um espaço para a realização imaginária de desejos inconscientes de seus membros a partir da articulação de desejos manifestos, formas de expressão e de organização grupal, o que lhe confere uma condição potencialmente terapêutica. Além disso, esses três aspectos também poderiam ser utilizados como critérios para a avaliação psicodinâmica de grupos infantis. 


\section{REFERÊNCIAS}

ALMEIDA, L.P. de \& ATALLAH, R.M.F. (2008) O conceito de repetição e sua importância para a teoria psicanalítica, Ágora, 11 (2), 203-218.

ÁLVAREZ, J.M.C. (1997). “Metodologia de la investigación grupal”, in GONZÁLEZ, P. (org.) Psicología de los grupos: teoria y aplicación. Madrid: Síntese.

ANZIEU, D. (1993) O grupo e o inconsciente: 0 imaginário grupal. São Paulo: Casa do Psicólogo.

BRASIL. MINISTÉRIO DA SAÚdE (1996) Conselho Nacional de Saúde. Resolução 196, de 10 de outubro de 1996. Diretrizes e normas regulamentadoras de pesquisas em seres humanos. Brasília (DF).

BRASILIENSE, L. da S. (1999) O desejo da psicanálise. Porto Alegre: Sulina. BEE, H. (1997) A criança em desenvolvimento. Porto Alegre: Artes Médicas.

CASTELLANOS, A.T., \& SÁNCHEZ-ESCÁRCEGA, J. (2003) Regresión y procesos inconscientes en el dispositivo grupal, Revista de Psicanálisis y Grupos, 1 (1), 44-67.

CODERCH, J. (1990) Teoría y técnica de la psicoterapia psicoanalítica. Barcelona: Herder.

CONTANDRIOPOULOS, A.P., CHAMPAGNE, F., POTVIN, L., DENIS, J.L., \& BOYLE, P. (1997) Saber preparar uma pesquisa: definição, estrutura, financiamento. São Paulo: Hucitec/Abrasco.

CUETO, A.M. del, \& FERNÁNDEZ, A.M. (1985) Lo grupal 2. Buenos Aires: Búsqueda.

DECHERF, G. (1986) Édipo em grupo: psicanálise e grupos de crianças. Porto Alegre: Artes Médicas.

FRANCO, S. de G. (2003) O brincar e a experiência analítica, Ágora, 6 (1), 45-59.

FREUD, S. (1987) Edição standard das obras psicológicas completas de Sigmund Freud. Rio de Janeiro: Imago.

(1895) "Projeto para uma psicologia científica", v.1.

(1900) “A interpretação dos sonhos”, v.4.

GAY, P. (1999) Freud: uma vida para nosso tempo. São Paulo: Companhia das Letras.

GOLDENBERG, M. (1998) A arte de pesquisar: como fazer pesquisa qualitativa em Ciências Sociais. Rio de Janeiro: Record.

GROMANN, R.M.G. \& BERLINCK, M.T. (2003) Sonho, um observatório psíquico: psicopatologia fundamental e subjetividade, Ágora, 6 (1), 139-152.

HANNS, L. (1999) A teoria pulsional na clínica de Freud. Rio de Janeiro: Imago.

KAËS, R. (1997) O grupo e o sujeito do grupo: elementos para uma teoria psicanalítica do grupo. São Paulo: Casa do Psicólogo.

.(2002) L'analogie du groupe et du revê: implication et développements, Psychologie Clinique Et Projective, (7), Montrouge: Dunod Revues, 3-16.

KERNBERG, O. (1998) Ideologia, conflicto y liderazgo en los grupos y organizaciones. Barcelona: Piados.

KRAMER, S., \& BYERLY, L.J. (1996) “Técnica da psicanálise da criança na latência”, in GLENN, J. \& SHARFMAN, M.A. (orgs.) Psicanálise e psicoterapia de crianças. Porto Alegre: Artes Médicas. 
KRUG, J.S. (2005) “A realização imaginária do desejo inconsciente num grupo terapêutico de crianças: a saída edípica e a entrada no período de latência”. Dissertação de mestrado em Psicologia Clínica não-publicada. PUCRS, Porto Alegre.

; SEMINOTTI, N. (2006) La realización imaginaria del deseo inconsciente en el grupo, Psicoanálisis y Grupos._México, DF: Ampag. v.1, n.4. julio-diciembre.

LAPLANCHE, J., \& PONTALIS, J.B. (1988) Vocabulário da psicanálise (10 ed.). São Paulo: Martins Fontes.

LEWIS, M. (1995) Tratado de psiquiatria da infância e adolescência. Porto Alegre: Artes Médicas.

MORAES, R., GALIAZZI, M. (2007) Análise textual discursiva. Ijuí: Editora Ijuí.

OLIVEIRA, H.C. de. (2002) Brincando de ser adulto: um estudo sobre os desejos num grupo de crianças. Fortaleza: Editora UFC.

PADILHA, B., \& MORAES, C.J. de. (2004) La ilusión grupal y la realidad: consecuencia en un grupo de espera. Disponível em: copsa.cop.es/ congresoiberoa/base/clinica/ct65.htm. Acesso em: 10/3/2006.

QUINODOZ, J.-M. (2004) A angústia de separação em psicanálise, Revista Brasileira de Psicoterapia, 1 (6), 7-20.

SARNOFF, C. A. (1995) Estratégias psicoterapêuticas nos anos de latência. Porto Alegre: Artes Médicas.

SEMINOTTI, N.A. (2003) O pequeno grupo organizador do ambiente de aprendizagem, [CD-ROM] Anais do II Congresso Latino-Americano de Dinâmica dos Grupos e III Congresso Brasileiro de Dinâmica Interpessoal. Porto Alegre: ID Agência Digital.

; N., BORGES, B.G.; CRUZ, J.L. (2004) O pequeno grupo como organizador do ambiente de aprendizagem, Psico-USF, 9 (2), 181-189.

SIGAL, A.M. (1989) Psicanálise, grupos, instituição pública, Percurso, (2), $40-45$.

SOIFER, R. (1987) Psiquiatria infantil operativa: psicologia evolutiva. Porto Alegre: Artes Médicas.

TAllaferro, A. (1996) Curso básico de psicanálise. São Paulo: Martins Fontes,

VALADARES, J.M., \& VILLANI, A. (2004) Continuidade e ruptura no trabalho coletivo de professores. Instituto de Física da Universidade de São Paulo. Disponível em: www.sbf1.if.usp.br/eventos/epef/viii/PDFs/ COCD5_1.pdf. Acesso em 10/3/2006.

VALLS, J. L. (1995) Diccionário freudiano. Barcelona: Julian Yebenes.

WEINMANN, A. de O. (2002) O conceito de desejo no "Projeto...", de Freud, Pulsional Revista de Psicanálise, 154 (15), 31-34.

Jefferson Silva Krug

jeffsilkrug@yahoo.com.br

Nedio Seminotti

nedio.seminotti@pucrs.br 
Figura 1: Categorias de análise dos dados

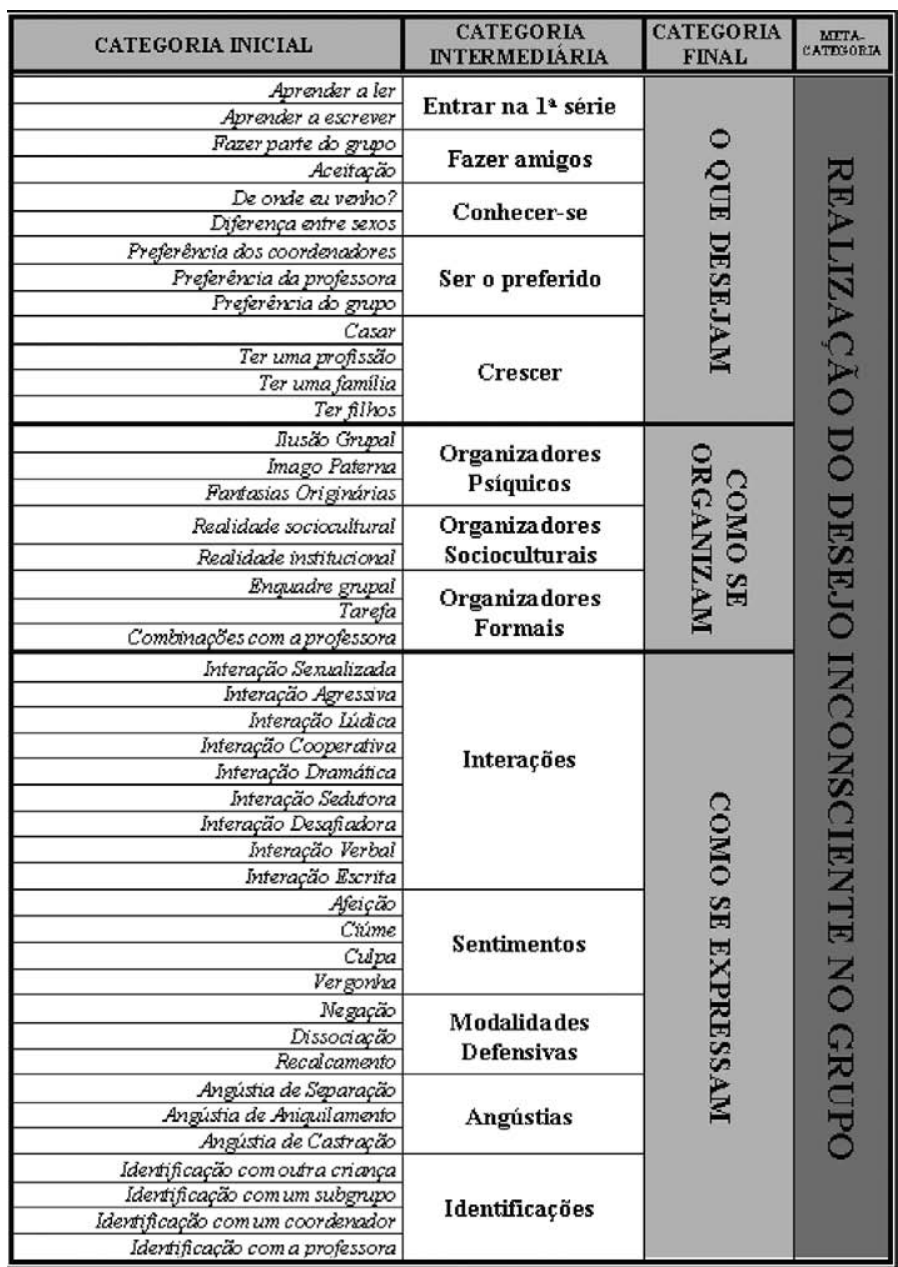

